\title{
Rental externality, tenure security, and housing quality
}

\author{
Shinichiro Iwata \\ Faculty of Economics, University of Toyama \\ 3190, Gofuku, Toyama, 930-8555, Japan \\ Phone: +81-76-445-6425, Fax: +81-76-445-6419 \\ E-mail: iwata@eco.u-toyama.ac.jp \\ Hisaki Yamaga \\ School of Economics, Kwansei Gakuin University \\ 1-155, Uegahara Ichiban-cho, Nishinomiya, 662-8501, Japan \\ Phone: +81-798-54-6139 Fax: +81-798-51-0944 \\ E-mail: yamaga@kwansei.ac.jp
}

\begin{abstract}
This paper considers two tenure modes - owner- and renter-occupied housing - and models the effect of the rental externality and tenure security on single-family housing quality. We show that both rental externality and tenure security reduce renter-occupied housing quality when the user's utilization, which reduces the quality of the accommodation, and the owner's maintenance, which raises quality, are substitutes. Using singlefamily housing data in Japan, we obtain empirical results that are consistent with theoretical predictions. These results indicate that conventional wisdom - that the quality of renter-occupied housing is lower than that of owner-occupied housing-is supported for single-family housing in Japan.
\end{abstract}

Keywords: Rental externality; Tenure security; Housing quality

JEL classification: R38; K11 


\section{Introduction}

There exist many rental housing properties with inadequate maintenance in the urban areas of Japan. According to conventional wisdom, the quality of renter-occupied housing is lower than that of owner-occupied housing. We offer a theoretical model and empirical results to test whether or not conventional wisdom is supported for single-family houses in Japan.

There may be two mechanisms for explaining deterioration in rental housing quality. First, a rental externality, defined by Henderson and Ioannides (1983), is a deterioration mechanism for rental housing. Henderson and Ioannides argued that in rental housing contracts, the right to use an asset is temporarily transferred to the tenant. Because tenants, unlike owner-occupiers, do not necessarily care about future asset values, they tend to overutilize dwellings. This leads to excessive deterioration of housing properties. This type of incentive problem occurs because the detection of overuse is either too costly or not feasible for the lessor (Benjamin et al. 1995). Galster (1983) found empirical evidence that owner-occupied housing requires a higher maintenance effort and has a lower incidence of housing problems than renter-occupied housing. Shilling et al. (1991) concluded that rental housing depreciates faster than owner-occupied housing. ${ }^{1}$

Secondly, the security of tenure rights, such as extensions in tenure duration that provide protection against eviction, also affect rental housing quality. Tenure security is complemented by rent control, because without price regulation, the landlord can evict the tenant using rent increases. A variety of forms of rent control exists in the world. Rent control forces rent below market clearing levels. Tenancy rent control governs rent increases within a tenancy, but has no power between tenancies (Arnott 2003). Contract-renewal rent control governs rent increases not only within a tenancy, but also after tenancy (Seko and Sumita 2007). In Japan, to prevent eviction through rent increases when the term of the tenancy expires, judicial precedents from tenancy suits have established that the rent for an incumbent tenant, called

\footnotetext{
${ }^{1}$ Harding et al. (2000) argued that owners also have incentives to undermaintain their housing in the following two circumstances. The first is because of the inability of prospective buyers to fully observe past seller maintenance, and the second is a result of the limited liability of borrowers in the event of mortgage default.
} 
here contract-renewal rent, is not permitted to exceed the rent, called market rent, of similar newly rented units. That is, the tenant retains the option to renew the leasehold coupled with a below-market price forced on the landlord. This control does not perfectly protect against eviction; however, it indirectly increases the probability of renewal, and consequently ex ante increases the length of the lease. Albon and Stafford (1990), Arnault (1975), Frankena (1975), Kanemoto (1990), Kiefer (1980), Moorhouse (1972), and Seshimo (2003) developed theoretical models to examine the impact of rent control (tenure security) on the maintenance of rental dwellings. They showed that because rent control may reduce the profit of rental housing, landlords reduce maintenance levels. Gyourko and Linneman (1990) found empirical evidence that rent-controlled units are more likely to deteriorate than uncontrolled units. Sims (2007) found that ending rent control leads to a significant reduction in chronic problems such as holes in walls or floors, chipped or peeling paint, plaster damage, and loose railings. This empirical result implies that rent control creates an overutilization problem in the tenant.

The first contribution of this paper is developed from a theoretical model and empirical results that incorporate the two mechanisms: the rental externality and tenure security. On the one hand, the influence of the rental externality on the quality of single-family house is captured by comparing across the tenure mode. On the other hand, the influence of tenure security on single-family housing quality is captured by comparing within the tenure mode. The preceding studies, however, explored only one side of the mechanism: either the rental externality or tenure security.

As mentioned, a large number of theoretical economic models and empirical results have supported conventional wisdom. Several papers, however, have demonstrated that these results are not robust. First, the empirical results of Gatzlaff et al. (1998) are inconsistent with theoretical models of the rental externality. They have found only weak evidence that maintenance rates differ between owner- and renter-occupied housing. Furthermore, they have established that owner-occupied housing depreciates relative to renter-occupied housing in some submarkets. Secondly, Olsen (1988) argued that if tenants maintain the quality of their housing, rent control (tenure security) does not necessarily reduce the quality of rental housing. This 
is because rent reductions are transfers from landlords to tenants. Therefore, the theory is ambiguous regarding the effect of tenure security on quality. Moon and Stotsky (1993) found empirical evidence that rent control leads to deterioration in housing quality; however, the effect is weak. They hypothesized that tenants in rent-controlled units are more likely to engage in self-maintenance, compensating for a lack of maintenance by landlords.

The second contribution of the paper is the finding that the rental externality and tenure security help support conventional wisdom, despite the above counterexamples. First, all previous theoretical models examined the decisions of owners and users in isolation. Olsen (1988) considered both, but he modeled a switching of maintenance responsibility between the landlord and the tenant. In fact, and as put forward by Miceli (1992), both decisions affect housing quality. In this paper, we simultaneously consider an investment in housing from the owner's perspective and the user's perspective, and examine the effect of the rental externality and tenure security on the quality of single-family dwelling. Secondly, in previous theoretical models, a tenant's investment has been found to have completely different effects on housing quality. Kanemoto (1990), Miceli (1992), and Olsen (1988) assumed that a tenant's investment has positive effects on rental housing quality, whereas Henderson and Ioannides (1983) assumed that it has negative effects. In this paper, we examine these two polar cases.

The main results are as follows. We find that theory is unambiguous on the effect of the rental externality and tenure security on single-family housing quality when we assume that a tenant's investment has negative effects on housing quality. That is, the quality of renter-occupied single-family housing is lower than that of owner-occupied single-family housing because of the rental externality when the user's utilization, which reduces the quality of the accommodation, and the owner's maintenance, which raises quality, are substitutes. Furthermore, tenure security further reduces the quality of single-family rental housing in this case. These results are consistent with conventional wisdom. Considering the rental externality and tenure security jointly, our empirical results, which used the sample of single-family houses from the 1998 Japanese Housing Demand Survey (JHDS), confirm the above theoretical predictions. Therefore, conventional wisdom is empirically supported for single-family dwellings 
in Japan.

The remainder of the paper is organized as follows. In Section 2, we first present a benchmark theoretical model without tenure security and investigate the effect of the rental externality on housing quality. We then introduce tenure security. The data and empirical model used are discussed in Section 3, along with the empirical results. In Section 4, we discuss some considerations of the theoretical model and empirical results. Section 5 summarizes the main conclusions of the paper.

\section{The model}

\subsection{The effects of the rental externality}

A single-family housing unit can be owned or rented. Accordingly, there are two entities involved: (i) the owner of the housing (the landlord); and (ii) the user of the housing (the tenant). In this paper, we suggest that housing can be owned and used under the following two tenure modes. The first type is owner-occupied single-family housing, in which the housing unit is owned by an owner who leases it to himself or herself. In this case, entities (i) and (ii) are the same individual. The second type is renter-occupied single-family housing, in which the housing unit is owned by a landlord who leases it to a tenant.

In this section, we consider a two-period model without tenure security in which we focus only on the effects of the rental externality on single-family housing quality. We introduce and define tenure security in the next section.

Because we focus on the quality of housing, we assume that housing comprises a single unit and that its construction cost is 0 . At the beginning of period 1, a landlord and a tenant make a one-period lease contract. The landlord offers the tenant of the dwelling with given housing quality a fixed rent $P_{1}$, and the tenant accepts the offer. Both the landlord and the tenant undertake investment during period 1 . Let $m$ be the maintenance undertaken by the landlord to mitigate quality deterioration during period 1 at cost $c(m)$, for which $c_{m}>0$ and $c_{m m}>0$, and $t$ be the input undertaken by the tenant in period 1 at cost $g(t)$, for which $g_{t}>0$ and

$g_{t t}>0$. The details of $t$ are discussed below. Following Henderson and Ioannides (1983) and 
Kanemoto (1990), we assume that the landlord and the tenant observe $t$ and $m$, but they are not verifiable. This implies that the contract in period 1 cannot specify the levels of $t$ and $m$. As Kanemoto (1990) argued, if a complete contingent contract can be written and enforced, cross-tenure differences do not matter at all. The tenant derives utility of $v_{1}(t)$, which can be expressed in pecuniary terms, in period 1 from housing. The tenant's input has positive effects for his/her own living conditions in the dwelling at a decreasing rate. Therefore, $v_{1 t}>0$, and $v_{1 t t}<0$. We assume $m$ is completed at the end of period 1. As a result, the current level of $m$ does not affect the tenant's utility in period 1 . The tenancy terminates at the end of period 1 .

The quality of single-family housing in period $2\left(q_{2}\right)$, which can be expressed in pecuniary terms, is assumed to be a function of $t$ and $m$. That is, $t$ and $m$ undertaken in period 1 have spillover effects on housing quality in period 2. Furthermore, additional investment expenditures are assumed to be zero in the second period. The offered rent in period $2\left(P_{2}\right)$ depends on the quality of housing $q_{2}$ and on a broader array of market conditions $\varepsilon_{2}$, e.g., inflation rate. We assume that $P_{2}$ is of an additive form; i.e., $P_{2}=q_{2}(t, m)+\varepsilon_{2}$. The maintenance increases $q_{2}(t, m)$ at a decreasing rate. Therefore, $q_{2 m}>0$, and $q_{2 m m}<0$.

The tenant's input has completely different effects on housing quality in the previous studies. On the one hand, if $t$ represents the effort to repair the unit, as described as Kanemoto (1990), Miceli (1992), and Olsen (1988), then $t$ has positive effects on housing quality. On the other hand, if $t$ represents the utilization intensity, as referred to by Henderson and Ioannides (1983), or a level of abuse, as described by Benjamin et al. (1995), $t$ has negative effects on housing quality, because it damages walls and floors. In reality, both home improvement and utilization may occur at the same time. For simplicity of the model, however, we consider the following two polar cases.

Definition 1 The tenant's input $t$ represents a utilization (u) or a home improvement (i); i.e., $t=u$ or $i$. If $t=u$, then $q_{2 u}<0$. We refer to the $q_{2 u}<0$ as case $U$. If $t=i$, then $q_{2 i}>0$. We refer to the $q_{2 i}>0$ as case $I$.

Representing a broader array of market conditions, $\varepsilon_{2}$ is a random variable for which both 
the owner and the user know the probability distribution function $f\left(\varepsilon_{2}\right)$, which is assumed to be uniform on the interval $\left[0, \bar{\varepsilon}_{2}\right]$, where $0<\bar{\varepsilon}_{2} \cdot{ }^{2}$

The initial tenant benefits from the tenant's input and the quality of single-family housing in period 2. Therefore, the initial tenant derives utility from housing of $v_{2}(t, m)=b_{2}\left(t, q_{2}(t, m)\right)$, which can be expressed in pecuniary terms, in period 2. We assume that $b_{2 t}>0(t=u$ or $i)$, and $\left(\partial b_{2} / \partial q_{2}\right)>0$. Then:

$$
v_{2 t}=b_{2 t}+\left(\frac{\partial b_{2}}{\partial q_{2}}\right) q_{2 t}
$$

is positive in case $\mathrm{I}(t=i)$, because $q_{2 i}>0$. In case $\mathrm{U}(t=u)$, the sign of Eq. (1) is indeterminate because $q_{2 u}<0$. However, we assume that Eq. (1) is positive in case U. This implies that the initial tenant values the positive side of utilization more than the negative side of it. We also assume that $v_{2 t t}<0(t=u$ or $i), v_{2 m}>0$, and $v_{2 m m}<0$.

We normalize the reservation utility level to 0 when the initial user lives in another dwelling in period 2. Then the maximum rent that he or she pays for the dwelling while enjoying a utility level of at least 0 is written as $v_{2}(t, m)$. Assume that the owner has no bargaining power. Then, at the beginning of the second period, the owner of the housing offers the rent $P_{2}=q_{2}(t, m)+\varepsilon_{2}$. The initial user renews the contract if the maximum rent is greater than or equal to the offered rent. Otherwise, he or she moves to other housing and obtains their reservation utility level.

To ensure that the initial tenant renews the contract, we assume the following:

$$
v_{2}(t, m)>q_{2}(t, m)
$$

This implies that the initial tenant values the extra utility from housing more than the market, or that potential buyers or tenants are not willing to pay as much for housing as the current user. We also assume that the tenant has a higher marginal benefit of $m$. Therefore:

$$
\forall t, m \quad v_{2 m}>q_{2 m} .
$$

\footnotetext{
${ }^{2}$ The effects of the rental externality on single-family housing quality do not depend on the functional form of the probability distribution function. The effects of tenure security on the quality of single-family rental housing, however, do depend on this simplifying assumption.
} 
In case $\mathrm{U}, v_{2 u}>q_{2 u}$ by assumption. To keep this relation in case I, we assume that $v_{2 i}>q_{2 i}$ for all $i$ and $m$. In sum:

$$
\forall t, m \quad v_{2 t}>q_{2 t} .
$$

Furthermore, we assume that:

$$
\exists \check{\varepsilon}_{2} \in\left(0, \bar{\varepsilon}_{2}\right] \quad v_{2}(t, m)<q_{2}(t, m)+\check{\varepsilon}_{2} .
$$

This implies that the maximum rent of the initial tenant can be less than the second-period rent if we consider the random variable $\varepsilon_{2}$. Therefore, this assumption ensures that the initial tenant can potentially move to other dwellings.

The efficient renewal-move condition can be written as follows:

$$
\left\{\begin{aligned}
F\left(\hat{\varepsilon}_{2}\right)=\operatorname{Pr}\left[v_{2}(t, m) \geq q_{2}(t, m)+\varepsilon_{2}\right] & \Rightarrow \quad \text { renewal, } \\
1-F\left(\hat{\varepsilon}_{2}\right)=\operatorname{Pr}\left[v_{2}(t, m)<q_{2}(t, m)+\varepsilon_{2}\right] \quad & \Rightarrow \text { move }
\end{aligned}\right.
$$

where $F\left(\varepsilon_{2}\right)$ is the cumulative distribution function (cdf) of $\varepsilon_{2}$. Eq. (2) implies that the tenant renews the contract if $\varepsilon_{2}$ is less than or equal to $\hat{\varepsilon}_{2}$, or otherwise moves to other housing in period 2. We refer to $\hat{\varepsilon}_{2}$ as the critical value. From Eq. (2), we have:

$$
\hat{\varepsilon}_{2}=\hat{\varepsilon}_{2}(t, m)=v_{2}(t, m)-q_{2}(t, m) \text {. }
$$

The critical value therefore depends on both $t$ and $m$.

Next, we consider the payoffs of each tenure mode. First, we examine renter-occupied single-family housing. Assume that the landlord and tenant are both risk neutral and have the same discount factor, set at unity. Then, from Eq. (2) and the assumption that $f\left(\varepsilon_{2}\right)$ is uniform, the utility of the tenant can be written as:

$$
V_{R}=v_{1}(t)-P_{1}-g(t)+\frac{\hat{\varepsilon}_{2}}{\bar{\varepsilon}_{2}}\left[v_{2}(t, m)-q_{2}(t, m)-\frac{\hat{\varepsilon}_{2}}{2}\right],
$$

where the subscript $R$ refers to renter-occupied housing.

Consider the landlord. For the case with no tenure security, the landlord obtains $q_{2}(t, m)+$ $\varepsilon_{2}$ whether or not the initial user renews the contract in period 2. Therefore, the landlord's profit can be written as:

$$
\Pi_{R}=P_{1}-c(m)+q_{2}(t, m)+\frac{\bar{\varepsilon}_{2}}{2} .
$$


The solutions to Eqs (3) and (4) satisfy, respectively:

$$
\begin{aligned}
\frac{\partial V_{R}}{\partial t} & =v_{1 t}+\frac{\hat{\varepsilon}_{2}}{\bar{\varepsilon}_{2}}\left(v_{2 t}-q_{2 t}\right)-g_{t}=0, \\
\frac{\partial \Pi_{R}}{\partial m} & =q_{2 m}-c_{m}=0 .
\end{aligned}
$$

These two equations define the tenant input function $t_{R}(m)$ and the landlord maintenance function $m_{R}(t){ }^{3}$ If the mixed partial derivative of the objective function with respect to $t$ and $m$ is negative, both the tenant input function and the landlord maintenance function are decreasing functions. That is, $t$ and $m$ are substitutes. We only consider this case following Miceli (1992). ${ }^{4}$ The equilibrium input levels, $t_{R}^{*}$ and $m_{R}^{*}$, can be found by simultaneously solving Eqs (5) and (6). ${ }^{5}$

Consider next the owner-occupied single-family housing. The payoff for owner-occupied housing is the sum of the initial user's payoff (Eq. (3)) and the homeowner's payoff (Eq. (4)). From the assumption that $f\left(\varepsilon_{2}\right)$ is uniform, the utility of the owner-occupant can be rewritten as:

$$
V_{O}=v_{1}(t)-g(t)-c(m)+\frac{\hat{\varepsilon}_{2}}{\bar{\varepsilon}_{2}} v_{2}(t, m)+\frac{\bar{\varepsilon}_{2}-\hat{\varepsilon}_{2}}{\bar{\varepsilon}_{2}}\left[q_{2}(t, m)+\frac{\bar{\varepsilon}_{2}+\hat{\varepsilon}_{2}}{2}\right]
$$

where the subscript $O$ refers to owner-occupied housing. Eq. (7) implies that the owner chooses $t$ and $m$ to maximize not only his or her utility (the sum of the first and fourth terms on the right-hand side), but also potential future tenants' or buyers' utilities (the last term on the right-hand side).

The first-order conditions for $t$ and $m$ are:

$$
\begin{aligned}
& \frac{\partial V_{O}}{\partial t}=v_{1 t}+\frac{\hat{\varepsilon}_{2}}{\bar{\varepsilon}_{2}}\left(v_{2 t}-q_{2 t}\right)+q_{2 t}-g_{t}=0, \\
& \frac{\partial V_{O}}{\partial m}=\frac{\hat{\varepsilon}_{2}}{\bar{\varepsilon}_{2}}\left(v_{2 m}-q_{2 m}\right)+q_{2 m}-c_{m}=0 .
\end{aligned}
$$

\footnotetext{
${ }^{3}$ We assume that an interior solution exists for each of the first-order conditions. This is assumed to hold throughout this paper.

${ }^{4}$ We also consider the case where $t$ and $m$ are complements; i.e., both the tenant input function and the landlord maintenance function become increasing functions. However, we do not obtain the result that both the rental externality and tenure security reduce the quality of single-family rental housing. Therefore, the theoretical predictions in the case of complements are inconsistent with conventional wisdom.

${ }^{5}$ The stability condition is assumed to hold throughout the paper. Furthermore, only the unique equilibrium is considered below.
} 
From this condition, we obtain the functions $t_{O}(m)$ and $m_{O}(t)$. The equilibrium input levels, $t_{O}^{*}$ and $m_{O}^{*}$, can be found by solving Eqs (8) and (9) simultaneously, which yields the intersection point of the two functions. ${ }^{6}$

Because owner-occupancy internalizes all payoff functions, the equilibrium input levels, $t_{O}^{*}$ and $m_{O}^{*}$, are efficient solutions. Therefore, we set $q_{2}\left(t_{O}^{*}, m_{O}^{*}\right)$ as the quality benchmark, and compare this with rental quality. As mentioned, comparing the equilibrium quality level across the tenure mode captures the effect of the rental externality.

\subsubsection{Case $U$}

First, compare Eq. (5) with Eq. (8) in case U where the tenant's input represents a utilization level. Therefore, $t$ in Eq. (5) and Eq. (8) is replaced by $u$. Because $q_{2 u}<0$, the marginal benefit of $u$ is larger in Eq. (5) than in Eq. (8), while the marginal costs are the same. Therefore, $u_{O}(m)<u_{R}(m)$ for all $m$. That is, the tenant ignores the landlord's future benefit and has an incentive to overutilize rental housing. Because we assume $v_{2 m}>q_{2 m}$, the marginal benefit of $m$ is smaller in Eq. (6) than in Eq. (9), while the marginal costs are the same. Therefore, landlord maintenance in renter-occupied single-family housing is smaller than that in owneroccupied single-family housing; i.e., $m_{O}(u)>m_{R}(u)$ for all $u$. The landlord ignores the value of the current tenant.

Figure 1 illustrates the equilibrium input levels in case U. The functions are negatively sloped, because $u$ and $m$ are substitutes. The equilibrium $E_{O}$ for owner-occupied single-family housing is given by the intersection of $u_{O}(m)$ and $m_{O}(u)$. As mentioned above, a switch from owning to renting causes the landlord's maintenance curve to shift down from $m_{O}(u)$ to $m_{R}(u)$, while the tenant's utilization curve shifts up from $u_{O}(m)$ to $u_{R}(m)$. The result is an equilibrium point for single-family rental housing $\left(E_{R}\right)$ at which there is an unambiguous decrease in maintenance $\left(m_{O}^{*}>m_{R}^{*}\right)$ and an unambiguous increase in utilization $\left(u_{O}^{*}<u_{R}^{*}\right)$. The quality of renter-occupied single-family housing therefore falls because of the rental externality; i.e.:

$$
q_{2}\left(u_{O}^{*}, m_{O}^{*}\right)>q_{2}\left(u_{R}^{*}, m_{R}^{*}\right) .
$$

\footnotetext{
${ }^{6}$ The second-order condition for a maximum is assumed to hold.
} 
Conventional wisdom is supported in case $\mathrm{U}$.

\subsubsection{Case I}

Now consider case I $(t=i)$. Because $q_{2 i}>0$, the marginal benefit of $i$ is smaller in Eq. (5) than in Eq. (8). The tenant ignores the value of the building to the future tenant; consequently, $i_{O}(m)>i_{R}(m)$ for all $m$. We also have $m_{O}(i)>m_{R}(i)$ for all $i$, because the marginal benefit of $m$ is smaller in Eq. (6) than in Eq.(9). Similarly to case U, the landlord ignores the value of the current tenant.

Therefore, a switch from owning to renting causes both the tenant's improvement curve and the landlord's maintenance curve to shift down because of the rental externality, e.g., from $m_{O}(i)$ to $m_{R}(i)$ and from $i_{O}(m)$ to $i_{R}(m)$ as in Figure 2. That is, for any given maintenance level by the other entity, each entity provides less than the efficient level of maintenance.

In equilibrium, there are three possible outcomes, depending on the magnitudes of the shifts in the tenant's improvement curve and the landlord's maintenance curve. If the relative size of the shifts are not different, then $i_{O}^{*}>i_{R}^{*}$ and $m_{O}^{*}>m_{R}^{*}$ in equilibrium. Because both landlord and tenant inputs are maintenance in case I, the rental externality reduces singlefamily rental housing quality. However, as in Figure 2, if the tenant's improvement decreases substantially while the landlord's maintenance decreases just a little, the equilibrium becomes $i_{O}^{*}>i_{R}^{*}$ and $m_{O}^{*}<m_{R}^{*}$. In contrast, if the landlord's maintenance decreases substantially while the tenant's improvement decreases just a little, the equilibrium becomes $i_{O}^{*}<i_{R}^{*}$ and $m_{O}^{*}>m_{R}^{*}$. The latter two possible outcomes show that the maintenance level of one of the parties exceeds the optimal level. Therefore, it is possible for the quality of renter-occupied single-family housing to exceed that of owner-occupied single-family housing. In sum, the effect of the rental externality on housing quality is ambiguous in case I. Gatzlaff et al. (1998) found no evidence of differences in housing quality between owner- and renter-occupied housing. Our model can derive this in case I. 


\subsection{The effects of tenure security}

In this section, we define and introduce tenure security into the model. As mentioned, the effect of tenure security on single-family housing quality varies within the tenure mode. Tenure security, however, has no effect on owner-occupied single-family housing. Therefore, we only consider single-family rental housing.

Tenure security has a variety of forms in the world as noted in Section 1. We now consider the Japanese case prior to the empirical analysis of Japan below. Japan is a country that shares a common feature with many other countries in the world. That is, tenure security is complemented by rent control. In Japan, to prevent eviction by a rent increase, judicial precedents from tenancy suits have established that the rent for an incumbent tenant, called here contract-renewal rent, is not permitted to exceed the rent, called market rent, of similar newly rented units. That is, the tenant retains the option to renew the leasehold coupled with a below-market price forced on the landlord. In fact, contract-renewal rents approved by the courts were lower than similar market rents when market rents increased markedly in Japan. The regulatory effect of this judicial precedent is called contract-renewal rent control. Therefore, in this paper, we define the Japanese tenant protection legislation as follows.

Definition 2 The tenant has an option to renew the contract with the contract-renewal rent $(1 / \alpha) P_{2}$, where $\alpha(\alpha>1)$.

If both the landlord and the initial tenant expect this to occur, the initial tenant's choice at the beginning of period 2 in a rental housing contract can be represented as follows:

$$
\left\{\begin{aligned}
F\left(\tilde{\varepsilon}_{2}\right)=\operatorname{Pr}\left\{v_{2}(t, m) \geq \frac{1}{\alpha}\left[q_{2}(t, m)+\varepsilon_{2}\right]\right\} & \Rightarrow \quad \text { renewal } \\
1-F\left(\tilde{\varepsilon}_{2}\right)=\operatorname{Pr}\left\{v_{2}(t, m)<\frac{1}{\alpha}\left[q_{2}(t, m)+\varepsilon_{2}\right]\right\} & \Rightarrow \quad \text { move. }
\end{aligned}\right.
$$

The critical value changes as follows:

$$
\tilde{\varepsilon}_{2}=\tilde{\varepsilon}_{2}(t, m, \alpha)=\alpha v_{2}(t, m)-q_{2}(t, m) \text {. }
$$

Eq. (11) shows that it is possible that the initial tenant may not be able to renew the contract under the Japanese tenant protection legislation. Because $\partial \tilde{\varepsilon}_{2} / \partial \alpha>0$, however, $\alpha$ indirectly 
increases the probability of renewal, and consequently increases the length of the lease in the ex ante view. This means that contract-renewal rent control complements tenure security. Therefore, $\alpha$ may imply the degree of tenure security. ${ }^{7}$

Noting Eq. (11) and the form of $f\left(\varepsilon_{2}\right)$, the utility of the tenant becomes:

$$
V_{R}^{S}=v_{1}(t)-P_{1}-g(t)+\frac{\tilde{\varepsilon}_{2}}{\bar{\varepsilon}_{2}}\left[v_{2}(t, m)-\frac{1}{\alpha} q_{2}(t, m)-\frac{1}{\alpha} \frac{\tilde{\varepsilon}_{2}}{2}\right],
$$

where superscript $S$ refers to the case with tenure security.

In the case of tenure security, the landlord can obtain $q_{2}(t, m)+\varepsilon_{2}$ when the initial tenant moves to other housing in period 2 . However, he or she only obtains $(1 / \alpha)\left[q_{2}(t, m)+\varepsilon_{2}\right]$ when the initial tenant renews the contract. Therefore, the profit for the landlord is as follows:

$$
\Pi_{R}^{S}=P_{1}-c(m)+\frac{\tilde{\varepsilon}_{2}}{\bar{\varepsilon}_{2}} \frac{1}{\alpha}\left[q_{2}(t, m)+\frac{\tilde{\varepsilon}_{2}}{2}\right]+\frac{\bar{\varepsilon}_{2}-\tilde{\varepsilon}_{2}}{\bar{\varepsilon}_{2}}\left[q_{2}(t, m)+\frac{\bar{\varepsilon}_{2}+\tilde{\varepsilon}_{2}}{2}\right] .
$$

The first-order conditions for Eqs (12) and (13) are:

$$
\begin{gathered}
\frac{\partial V_{R}^{S}}{\partial t}=v_{1 t}+\frac{\tilde{\varepsilon}_{2}}{\bar{\varepsilon}_{2}}\left(v_{2 t}-\frac{1}{\alpha} q_{2 t}\right)-g_{t}=0, \\
\frac{\partial \Pi_{R}^{S}}{\partial m}=\left(\frac{\tilde{\varepsilon}_{2}}{\bar{\varepsilon}_{2}} \frac{1}{\alpha}+\frac{\bar{\varepsilon}_{2}-\tilde{\varepsilon}_{2}}{\bar{\varepsilon}_{2}}\right) q_{2 m}+\frac{\tilde{\varepsilon}_{2 m}}{\bar{\varepsilon}_{2}}\left(\frac{1}{\alpha}-1\right)\left(q_{2}+\tilde{\varepsilon}_{2}\right)-c_{m}=0,
\end{gathered}
$$

respectively. We obtain $t_{R}^{S}(m, \alpha)$ from Eq. (14), and $m_{R}^{S}(t, \alpha)$ from Eq. (15). The equilibrium is the intersection point of $t_{R}^{S}(m, \alpha)$ and $m_{R}^{S}(t, \alpha)$, and is denoted by $t_{R}^{s}$ and $m_{R}^{s}$.

\subsubsection{Case $U$}

Now compare the equilibrium input levels of renter-occupied housing with and without tenure security in case $\mathrm{U}(t=u)$. Again $t$ in Eq. (5) and Eq. (14) is replaced by $u$. Comparing Eq. (5) and Eq. (14) indicates that $u_{R}(m)<u_{R}^{S}(m, \alpha)$ for all $m$, given $\alpha>1$. The marginal profit of $u$ is increased by tenure security; consequently, wear and tear caused by the tenant's activities increases. This result is consistent with Sims (2007). Comparing Eq. (6) and Eq.

\footnotetext{
${ }^{7}$ In reality, there is the case where (contract-renewal) rent control is not binding. In this case $\alpha=1$. However, we consider only the case where the control is binding $(\alpha>1)$, because we are concerned with the effect of tenure security.
} 
(15) reveals that $m_{R}(u)>m_{R}^{S}(u, \alpha)$ for all $u$, given $\alpha>1$. The marginal profit of $m$ is reduced by tenure security; therefore, the landlord reduces home maintenance. This result is consistent with Kanemoto (1990) and Seshimo (2003).

Figure 1 compares the equilibrium with tenure security $\left(E_{R}^{S}\right)$ and without it $\left(E_{R}\right)$ for case U. Tenure security causes the landlord's maintenance curve to shift downward from $m_{R}(u)$ to $m_{R}^{S}(u, \alpha)$, whereas the tenant's utilization curve shifts upward from $u_{R}(m)$ to $u_{R}^{S}(m, \alpha)$. Therefore, the intersection of the new curves moves to the northwest. As a result, tenure security certainly increases $u$ and decreases $m$ in equilibrium; i.e., $u_{R}^{*}<u_{R}^{s}$ and $m_{R}^{*}>m_{R}^{s}$. The quality of renter-occupied single-family dwelling, therefore, is lowered because of tenure security; i.e.:

$$
q_{2}\left(u_{R}^{*}, m_{R}^{*}\right)>q_{2}\left(u_{R}^{s}, m_{R}^{s}\right) .
$$

From Eq. (16), the model is unambiguous on the effect of tenure security on single-family housing quality in case U.

Figure 1 also shows that the levels of both overutilization and undermaintenance according to the rental externality are distorted more by tenure security. Combining Eq. (10) and Eq. (16), we find that tenure security accelerates the deterioration of rental housing quality induced initially by the effect of the rental externality in case U.

\subsubsection{Case $I$}

In case I $(t=i)$, we have $i_{R}(m)<i_{R}^{S}(m, \alpha)$ for all $m$ and $m_{R}(i)>m_{R}^{S}(i, \alpha)$ for all $i$, given $\alpha>1$. As in Figure 2, the tenant's improvement curve shifts upward, because tenure security increases the probability of renewal to capture the benefit of the tenant's own investment. Tenure security, however, causes the landlord's maintenance curve to shift downward, because tenure security reduces the landlord's profit. Therefore, the effect of tenure security on singlefamily housing quality in case I is ambiguous because $i_{R}^{*}<i_{R}^{s}$ and $m_{R}^{*}>m_{R}^{s}$ in equilibrium. Olsen (1988) argued that tenants in rent-controlled units maintain their housing, compensating for landlords' maintenance. Therefore, rent control does not necessarily deteriorate rental housing quality. In our model, tenants in contract-renewal rent-controlled units maintain their 
housing, compensating for inadequate landlords' maintenance in case I. This result is consistent with Olsen (1988).

\section{$3 \quad$ Empirical analysis}

\subsection{The data and the empirical model}

Our theoretical model predicts that the quality of renter-occupied single-family housing will deteriorate relative to that of owner-occupied single-family housing according to the rental externality, when the user's input, which reduces the quality of the accommodation, and the owner's maintenance, which raises quality, are substitutes. In addition, tenure security accelerates the deterioration of single-family rental housing. These theoretical predictions are consistent with conventional wisdom. In contrast, the effects of the rental externality and tenure security on rental housing quality are indeterminate when the user's investment raises the quality of the accommodation. In this section, we empirically test whether conventional wisdom is supported or not in Japan. Unlike previous studies, we simultaneously consider the effect of the rental externality and tenure security on the quality of renter-occupied singlefamily housing.

We obtain the data from the 1998 JHDS. The JHDS is conducted by the Japanese Ministry of Land, Infrastructure, and Transport every five years. The 1998 JHDS collected microlevel cross-sectional data on 100,000 households in Japan. We use the sample of households who dwell in a single-family house. In the theoretical model, both the tenant's input and the landlord's maintenance have an important influence on single-family housing quality. These variables, however, are not available. Therefore, we cannot directly estimate the quality of housing. Some previous studies addressed this problem by looking at the physical condition of housing units (Gyourko and Linneman 1990; Moon and Stotsky 1993; Sims 2007). Information on the degree of dilapidation is also reported by the surveyor in the JHDS using the following three categories: repairs not needed, or slight repairs needed; major repairs needed; and dilapidated beyond repair. ${ }^{8}$ As in Gyourko and Linneman (1990), we refer to housing needing no

\footnotetext{
${ }^{8}$ Information on the degree of dilapidation in a more recent survey (the 2003 JHDS) has changed. Therefore,
} 
or slight repairs as sound. Housing needing major repairs and dilapidated housing are referred to as not sound. By defining the dummy variable Sound, the following probit specification is estimated:

$$
\operatorname{Pr}(\text { Sound }=1)=\Phi\left(x^{\prime} \beta\right)
$$

where $\operatorname{Pr}($ Sound $=1)$ is the probability that the unit is sound, $\Phi$ is the standard normal cdf, $x$ is a vector of explanatory variables, and $\beta$ is the vector of probit coefficients. ${ }^{9}$

Table 1 defines the variables that are used in the estimation of Eq. (17), and Table 2 describes their frequencies, means, or modes. Screening the data for complete information on the selected variables, we obtain a sample of 41,253 observations on owner- and renteroccupied single-family houses. Of these, 94.6\% (39,013 dwellings) are owner-occupied singlefamily houses, and 5.4\% (2,240 dwellings) are renter-occupied single-family houses. Note that $90.1 \%$ of owner-occupied units are in structures reported as being in sound condition, while $75.5 \%$ of renter-occupied units are reported as sound.

We design the following three-way interaction terms to investigate the rental externality and tenure security:

$$
\text { Renter-occupied } \times \text { Building age }_{j} \times{\text { Moving } \text { time }_{k} .}
$$

First, as mentioned in our theoretical model, the propensity to utilize and maintain the dwelling varies across the tenure mode because of the rental externality. Therefore, we use the renter-occupied housing dummies, with owner-occupied housing being the reference tenure mode, which controls for building age and moving time, to capture the effect of the rental externality by using the observations on owner- and renter-occupied single-family housing. We control building age $j$ (built pre-1970; built 1971 - 1980; built 1981 - 1990; and built 1991 we use the 1998 JHDS.

${ }^{9}$ The dummy variable, Sound, is defined as follows:

$$
\begin{aligned}
& \text { Sound }=1 \text { if } q_{2}>\bar{q}_{2}, \\
& \text { Sound }=0 \text { otherwise, }
\end{aligned}
$$

where $\bar{q}_{2}$ is the critical quality of not being sound. 
1998), because the older the building, the lower the probability it is in sound condition. We also control tenancy duration, because the longer-duration renter-occupied housing is protected by tenure security. The JHDS records the year of relocation to the present dwelling; therefore, we control moving time $k$ (moved in pre-1970; moved in 1971 - 1980; moved in 1981 - 1990; and moved in 1991 - 1998). ${ }^{10}$ In the older category, periods for tenancy duration are longer. Therefore, we assume that tenure security is less likely to influence the group with the most recent moving time. We set owner-occupied housings constructed between 1991 and 1998, into which respondents moved during the same period, as the reference group. Then, the sign of the renter-occupied housing dummies, where $k=1991-1998$, shows us the effect of the rental externality.

Secondly, we examine how the estimated coefficients of the moving-in year dummies vary from the benchmark years, $(k=1991-1998)$ in Eq. (18), to capture the effect of tenure security. We expect that the coefficients for the renter-occupied housing dummies (renteroccupied housing dummies in Eq. (18) are 1) vary across moving-in year dummies, because the longer-duration housing is protected by tenure security. As suggested by theory, the propensity to utilize and maintain the dwelling varies within the tenure mode because of tenure security. On the other hand, we expect that the quality of owner-occupied single-family housing does not depend on tenancy duration, because tenure security has no impact on this type of dwelling. Therefore, we should observe that the coefficients of the Building age ${ }_{j} \times$ Moving time $_{k}$ dummies (note that the reference tenure mode is owner-occupied housing) remain constant.

\subsection{Estimation results}

Table 3 presents the probit coefficients and marginal effects of the rental externality and tenure security on single-family housing quality. ${ }^{11}$

The coefficients in bold indicate the effect of the rental externality. The statistically signif-

\footnotetext{
${ }^{10}$ If the current house was rebuilt on the same site after the respondent moved in, we have equated the move-in year to the rebuilt year.

${ }^{11}$ The marginal effects are calculated as:$$
\left.\operatorname{Pr}(\text { Sound }=1)\right|_{\text {dummy variable }=1}-\left.\operatorname{Pr}(\text { Sound }=1)\right|_{\text {dummy variable }}=0 .
$$ 
icant sign of the bold coefficients for the renter-occupied housing dummy (except for housing moved into between 1991 and 1998 and constructed before 1970) implies that renter-occupied single-family dwellings has a lower probability of being in sound condition than owner-occupied single-family units. These results suggest that the rental externality reduces the quality of renter-occupied single-family dwellings in Japan.

The coefficients in italics indicate the effect of tenure security on renter-occupied singlefamily dwellings. Note that all of these figures have a statistically significant negative sign. Figure 3 shows the relationships between tenancy duration and housing quality for owneroccupied single-family houses, which are obtained from Table 3. As expected, Figure 3 shows that the quality of owner-occupied single-family housing does not depend much on tenancy duration. By adding the marginal effect of owner-occupied housing with moving time $k$ controlled by building age $j(j \times k)$ and that of the renter-occupied housing dummy, we obtain the gross marginal effect of tenure security on renter-occupied housing measured by $j \times k$. For example, the gross marginal effect of renter-occupied housing with move-in period 1971 to 1980 constructed between 1971 and 1980 becomes $(-0.130-0.103)=-0.233(-23.3 \%)$. Figure 4 shows that the more recent the move-in date, the smaller the absolute value of the marginal effect (except for housing moved into between 1981 and 1990 and constructed before 1970). This implies that the longer the tenancy duration, the greater the extent of deterioration. Therefore, tenure security further reduces the quality of single-family rental housing in Japan.

The result confirms the theoretical prediction of case U where the tenant's input represents utilization, because both the rental externality and tenure security reduce the quality of singlefamily rental dwellings. ${ }^{12}$

\section{Discussion}

There are several considerations in the interpretation of both the theoretical and the empirical results. The first consideration is related to additional investment. Kanemoto (1990) theoret-

\footnotetext{
${ }^{12}$ The landlord may structure a lease to induce responsible behavior by the tenant. Benjamin et al. (1995) showed that some form of variable lease payments, e.g., imposing a security deposit or penalty fee, or discounting the rent for good users, may mitigate overutilization by the tenant. Although this information is not available, our results show that variable lease payments do not work well in the Japanese rental housing market.
} 
ically examined the relationship between additional investment and tenure mode; however, we ignore the additional investment strategies in period 2. That is, all investment decisions are determined in the first period in our theoretical model. Moon and Stotsky (1993) showed the principal advantage of using a longitudinal data set for investigating the effect of rent control. This may be because the dynamic decisions of maintenance are important for determining housing quality. Unfortunately, our empirical model cannot capture the dynamic change in housing quality, because the data set is cross-sectional. The second consideration is the link between the theoretical model and our empirical model. The theoretical model is a forwardlooking model. Because the landlord and the tenant anticipate the lower contract-renewal rent because of tenure security, they change their present input levels. This will change future housing quality. In contrast, the JHDS provides information on current housing quality. We try to capture the effects of tenure security on differences in housing quality between recent and earlier movers. Therefore, the time axis is different between the theoretical model and the empirical model. However, if the quality of housing in the future depends on the present level of inputs, then current housing quality may depend on the past level of inputs. This interpretation may combine the theoretical model with our empirical model. The third consideration is also the link between the theoretical analysis and the empirical analysis. Tenancy duration (stay or move decision) is an endogenous variable in the theoretical model; however, we treat it as exogenous in our empirical analysis. Using longitudinal data, Seko and Sumita (2007) estimated a proportional hazard model to investigate the effect of tenure security on tenancy duration in Japan. Their empirical results showed that tenure security depresses renter mobility. However, we cannot control this because our data set is cross-sectional, as mentioned above. These three issues remain for future research.

\section{Conclusion}

It is widely believed that the quality of renter-occupied housing is lower than that of owneroccupied housing as a result of the rental externality and tenure security. However, several papers have objected to this conventional wisdom. In this paper, we showed the conditions 
under which conventional wisdom is supported. Unlike the previous studies, we developed a model to determine simultaneously the effect of the rental externality and tenure security on the quality of single-family houing. We focused on both maintenance by the owner and utilization by the user. Although both tenant and landlord inputs are important, previous studies that have supported conventional wisdom have only examined these inputs in isolation. We first compared single-family housing quality across the tenure mode to obtain the effect of the rental externality. Then we compared the quality of single-family dwelling within the tenure mode to obtain the effect of tenure security. Our main theoretical results are summarized below.

Because owner-occupancy internalizes both the user's and the owner's net benefit, the input levels become efficient. In contrast, when both maintenance by the landlord, which raises the quality of the accommodation, and utilization by the tenant, which reduces quality, are not verifiable, and if they are substitutes, a rental contract for housing creates a rental externality problem: the initial tenant overutilizes the housing and the landlord undermaintains it. Therefore, in this case, the quality of renter-occupied single-family housing is lower than that of owner-occupied single-family housing because of the rental externality. Tenure security that is guaranteed by contract-renewal rent control in Japan lowers the contract-renewal rent, defined as the rent for an incumbent tenant, which is not permitted to exceed the rent for similar newly rented units. Therefore, tenure security further increases tenants' utilization and decreases landlords' maintenance. In this situation, tenure security accelerates deterioration of the quality of single-family rental housing in conjunction with the rental externality. These theoretical predictions are consistent with conventional wisdom. However, if tenants' input raises quality, the effect of the rental externality and tenure security on rental housing quality is indeterminate. Therefore, our model also supports the theoretically ambiguous case.

Using a cross-section of 41,253 observations on owner- and renter-occupied single-family houses from the 1998 JHDS, we tested our theoretical predictions empirically. Unlike the previous studies, our equation simultaneously considers the rental externality and tenure security. To test our theoretical predictions, we estimated a probit model: housing units are in sound condition or not. We obtained the following empirical results. 
The empirical test for the rental externality showed that renter-occupied single-family housing is less likely to be in sound condition than owner-occupied single-family housing. Furthermore, the empirical results confirmed that tenure security accelerates deterioration in the quality of single-family rental housing: renter-occupied units in longer tenancy are less likely to be in sound condition than units in shorter tenancy. Therefore, our empirical results confirm the theoretical predictions when tenants' utilization, which reduces quality, and landlords' maintenance, which raises quality, are substitutes. Conventional wisdom is empirically supported for single-family housing in Japan.

\section{Acknowledgement}

The authors would like to thank Shinsuke Kambe, Sunwoong Kim, Yoko Moriizumi, Hideki Mizukami, Hiroyuki Seshimo, and seminar participants at Kobe University of Commerce, Kyoto University, Sophia University, the University of Tokyo, Toyama University, Housing Research and Advancement Foundation of Japan, the JEA conference in Hiroshima, AsRES conference in Seoul and Delhi for their valuable suggestions. The authors would also acknowledge the helpful comments of two anonymous referees. All remaining errors are the sole responsibility of the authors. This research was supported by MEXT.KAKENHI (14730023 and 15730116). 


\section{References}

Albon RP, Stafford DC. Rent control and housing maintenance. Urban Studies 1990;27; $233-240$.

Arnault EJ. Optimal maintenance under rent control with quality constraints. American Real Estate and Urban Economic Association Journal 1975;3; 67-82.

Arnott R. Tenancy rent control. Swedish Economic Policy Review 2003;10; 89-121.

Benjamin JD, de la Torre C, Musumeci J. Controlling the incentive problems in real estate leasing. Journal of Real Estate Finance and Economics 1995;10; 177-191.

Frankena M. Alternative models of rent control. Urban Studies 1975;12; 303-308.

Galster GC. Empirical evidence on cross-tenure differences in home maintenance and conditions. Land Economics 1983;59; 107-113.

Gatzlaff DH, Green RK, Ling DC. Cross-tenure differences in home maintenance and appreciation. Land Economics 1998;74; 328-342.

Gyourko J, Linneman P. Rent controls and rental housing quality: a note on the effects of New York City's old controls. Journal of Urban Economics 1990;27; 398-409.

Harding J, Miceli TJ, Sirmans CF. Do owners take better care of their housing than renters? Real Estate Economics 2000;28; 663-681.

Henderson JV, Ioannides YM. A model of housing tenure choice. American Economic Review 1983;73; 98-113.

Kanemoto Y. Contract types in the property market. Regional Science and Urban Economics $1990 ; 20 ; 5-22$.

Kiefer D. Housing deterioration, housing codes and rent control. Urban Studies 1980;17; 53-62. 
Miceli TJ. Habitability laws for rental housing: the impact of tenant inputs. Urban Studies $1992 ; 29 ; 15-24$.

Moon C, Stotsky JG. The effect of rent control on housing quality change: a longitudinal analysis, Journal of Political Economy 1993;101; 1114-1148.

Moorhouse JC. Optimal housing maintenance under rent control. Southern Economic Journal 1972;139; 93-106.

Olsen EO. What do economists know about the effect of rent control on housing maintenance? Journal of Real Estate Finance and Economics 1988;1; 295-307.

Seko M, Sumita, K. Effects of government policies on residential mobility in Japan: income tax deduction system and the rental act. Journal of Housing Economics 2007;16; 167-188.

Seshimo H. Optimal tenant protection. Regional Science and Urban Economics 2003;33; $59-92$.

Shilling JD, Sirmans CF, Dombrow JF. Measuring depreciation in single-family rental and owner-occupied housing, Journal of Housing Economics 1991;1; 368-383.

Sims DP. Out of control: what can we learn from the end of Massachusetts rent control? Journal of Urban Economics 2007;61; 129-151. 
Table 1 Definition of variables

\begin{tabular}{|c|c|}
\hline Variable & Definition \\
\hline Sound & A binary variable indicating the unit is in sound condition. \\
\hline Renter-occupied & $\begin{array}{l}\text { A binary variable indicating the unit is renter-occupied single- } \\
\text { family housing. }\end{array}$ \\
\hline Built pre-1970 & A binary variable indicating the unit was built pre- 1970 . \\
\hline Built 1971-1980 & A binary variable indicating the unit was built $1971-1980$. \\
\hline Built 1981-1990 & A binary variable indicating the unit was built $1981-1990$. \\
\hline Built 1991-1998 & A binary variable indicating the unit was built $1991-1998$. \\
\hline Moved in pre-1970 & A binary variable indicating the household moved in pre- 1970 . \\
\hline Moved in $1971-1980$ & A binary variable indicating the household moved in 1971-1980. \\
\hline Moved in $1981-1990$ & A binary variable indicating the household moved in 1981-1990. \\
\hline Moved in 1991-1998 & A binary variable indicating the household moved in 1991-1998. \\
\hline Wooden & The building whose main frames are made of wood (reference). \\
\hline $\mathrm{SRC}$ & $\begin{array}{l}\text { A binary variable indicating the building whose main frames } \\
\text { are made of steel-reinforced concrete. }\end{array}$ \\
\hline Block & $\begin{array}{l}\text { A binary variable indicating the building whose outer walls are } \\
\text { made of blocks. }\end{array}$ \\
\hline Others & $\begin{array}{l}\text { A binary variable indicating the building whose main frames } \\
\text { are made of another construction material. }\end{array}$ \\
\hline Tokyo & $\begin{array}{l}\text { A binary variable indicating the unit is located in one of } 23 \\
\text { Tokyo wards. }\end{array}$ \\
\hline Large city & $\begin{array}{l}\text { A binary variable indicating the unit is located in one of } 12 \\
\text { major cities outside Tokyo. }\end{array}$ \\
\hline Other area & The unit is located in any other area (reference). \\
\hline Room & Number of rooms in the unit. \\
\hline Income & $\begin{array}{l}\text { Running number from } 1 \text { (the lowest) to } 9 \text { (the highest) of total } \\
\text { annual income (before tax) earned by all household members. }\end{array}$ \\
\hline Number of observations & 41,253 \\
\hline
\end{tabular}


Table 2 Frequency/mean/mode of variables

\begin{tabular}{lccc}
\hline Variable & All observations & Owner-occupied & Renter-occupied \\
\hline Sound & 89.3 & 90.1 & 75.5 \\
Renter-occupied & 5.4 & & \\
Built pre-1970 & 26.3 & 25.7 & 35.9 \\
Built 1971-1980 & 29.3 & 29.1 & 32.3 \\
Built 1981-1990 & 24.9 & 25.1 & 21.6 \\
Built 1991-1998 & 19.6 & 20.2 & 10.2 \\
Moved in pre-1970 & 22.7 & 23.5 & 8.4 \\
Moved in 1971-1980 & 26.2 & 27.1 & 10.1 \\
Moved in 1981-1990 & 26.0 & 26.1 & 24.6 \\
Moved in 1991-1998 & 25.1 & 23.3 & 57.0 \\
Wooden & 92.3 & 92.2 & 95.1 \\
SRC & 5.5 & 5.6 & 3.6 \\
Block & 0.4 & 0.4 & 0.3 \\
Others & 1.8 & 1.9 & 1.0 \\
Tokyo & 1.7 & 1.7 & 1.8 \\
Large city & 10.2 & 10.0 & 14.4 \\
Other area & 88.1 & 88.4 & 83.8 \\
Room & 6.0 & 6.1 & 4.0 \\
Income & 5 & 5 & 3 \\
Number of observations & 41,253 & 39,013 & 2,240 \\
\hline
\end{tabular}


Table 3 Probit coefficients and marginal effects

\begin{tabular}{|c|c|c|c|}
\hline Variable & Coefficient & Standard error & Marginal effect \\
\hline Intercept & $1.656^{* * *}$ & 0.051 & \\
\hline \multicolumn{4}{|l|}{ Built pre-1970 } \\
\hline Moved in pre-1970 & $-1.386^{* * *}$ & 0.042 & $-0.199^{* * *}$ \\
\hline Moved in $1971-1980$ & $-1.332^{* * *}$ & 0.078 & $-0.191^{* * *}$ \\
\hline Moved in $1981-1990$ & $-1.308^{* * *}$ & 0.099 & $-0.187^{* * *}$ \\
\hline Moved in 1991-1998 & $-1.380^{* * *}$ & 0.114 & $-0.198^{* * *}$ \\
\hline \multicolumn{4}{|l|}{ Built $1971-1980$} \\
\hline Moved in $1971-1980$ & $-0.911^{* * *}$ & 0.042 & $-0.130^{* * *}$ \\
\hline Moved in 1981-1990 & $-0.848^{* * *}$ & 0.074 & $-0.122^{* * *}$ \\
\hline Moved in $1991-1998$ & $-0.883^{* * *}$ & 0.089 & $-0.127^{* * *}$ \\
\hline \multicolumn{4}{|l|}{ Built 1981-1990 } \\
\hline Moved in $1981-1990$ & $-0.464^{* * *}$ & 0.045 & $-0.067^{* * *}$ \\
\hline Moved in 1991-1998 & $-0.479^{* * *}$ & 0.097 & $-0.069^{* * *}$ \\
\hline \multicolumn{4}{|l|}{ Built pre-1970 $\times$ Renter-occupied } \\
\hline Moved in pre-1970 & $-0.474^{* * *}$ & 0.095 & $-0.068^{* * *}$ \\
\hline Moved in $1971-1980$ & $-0.477^{* * *}$ & 0.134 & $-0.068^{* * *}$ \\
\hline Moved in $1981-1990$ & $-0.518^{* * *}$ & 0.127 & $-0.074^{* * *}$ \\
\hline Moved in 1991-1998 & -0.125 & 0.132 & -0.018 \\
\hline \multicolumn{4}{|l|}{ Built $1971-1980 \times$ Renter-occupied } \\
\hline Moved in $1971-1980$ & $-0.718^{* * *}$ & 0.129 & $-0.103^{* * *}$ \\
\hline Moved in $1981-1990$ & $-0.395^{* * *}$ & 0.118 & $-0.057^{* * *}$ \\
\hline Moved in $1991-1998$ & $-0.343^{* * *}$ & 0.107 & $-0.049^{* * *}$ \\
\hline \multicolumn{4}{|l|}{ Built $1981-1990 \times$ Renter-occupied } \\
\hline Moved in $1981-1990$ & $-0.641^{* * *}$ & 0.129 & $-0.092^{* * *}$ \\
\hline Moved in 1991-1998 & $-0.295^{* *}$ & 0.129 & $-0.042^{* *}$ \\
\hline \multicolumn{4}{|l|}{ Built 1991-1998 $\times$ Renter-occupied } \\
\hline Moved in 1991-1998 & $-0.407^{* * *}$ & 0.149 & $-0.058^{* * *}$ \\
\hline $\mathrm{SRC}$ & $0.190^{* * *}$ & 0.049 & \\
\hline Block & $-0.255^{* *}$ & 0.127 & \\
\hline Others & 0.111 & 0.092 & \\
\hline Tokyo & $-0.335^{* * *}$ & 0.063 & \\
\hline Large city & 0.046 & 0.030 & \\
\hline Room & $0.044^{* * *}$ & 0.006 & \\
\hline Income & $0.057^{* * *}$ & 0.005 & \\
\hline Number of observations & & 41,253 & \\
\hline Pseudo $\mathrm{R}^{2}$ & & 0.130 & \\
\hline Log-likelihood & & -12204.04 & \\
\hline
\end{tabular}

Bold figures capture the effect of the rental externality.

Italic figures capture the effect of tenure security.

${ }^{* * *}$ indicates significance at $1 \%{ }^{* *}$ indicates significance at $5 \%$ 


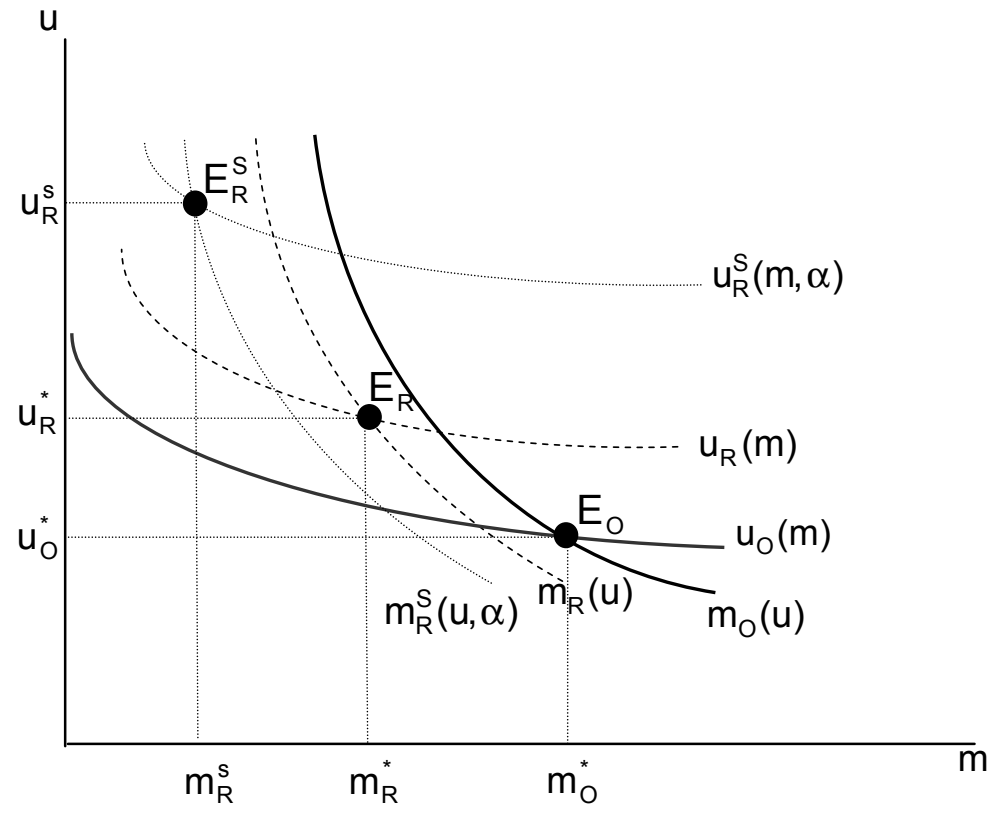

Fig. 1 Case U 


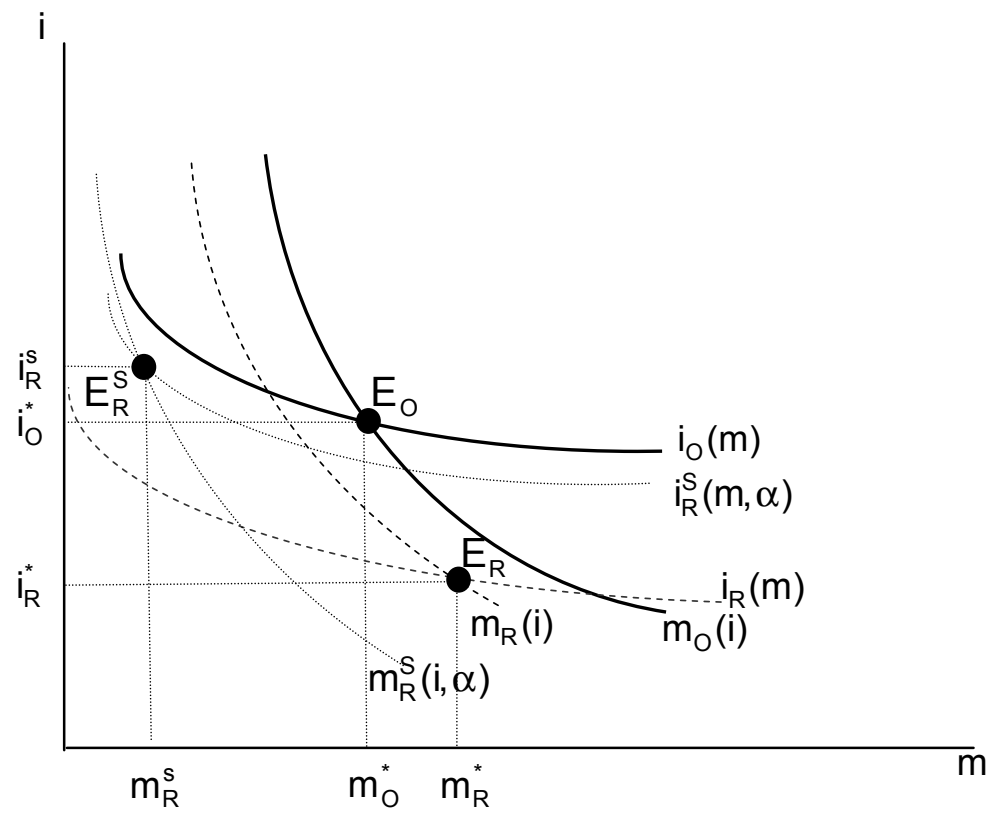

Fig. 2 Case I 


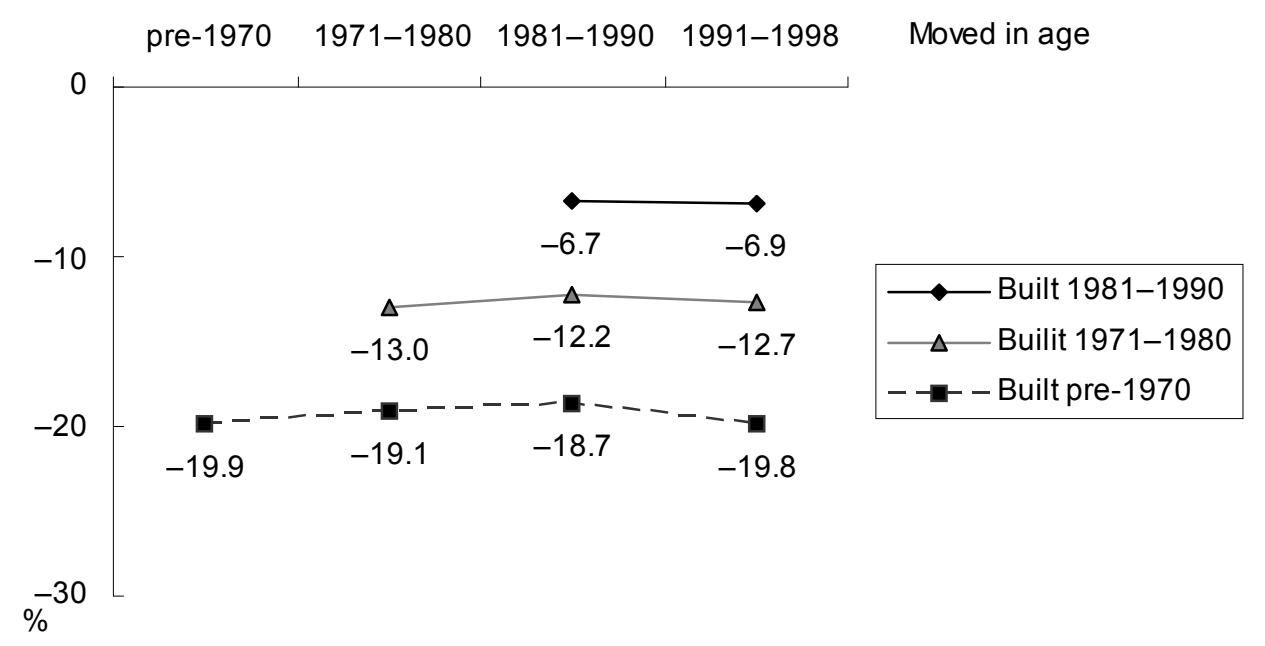

Fig. 3 The effect of tenure security on owner-occupied single-family housing 


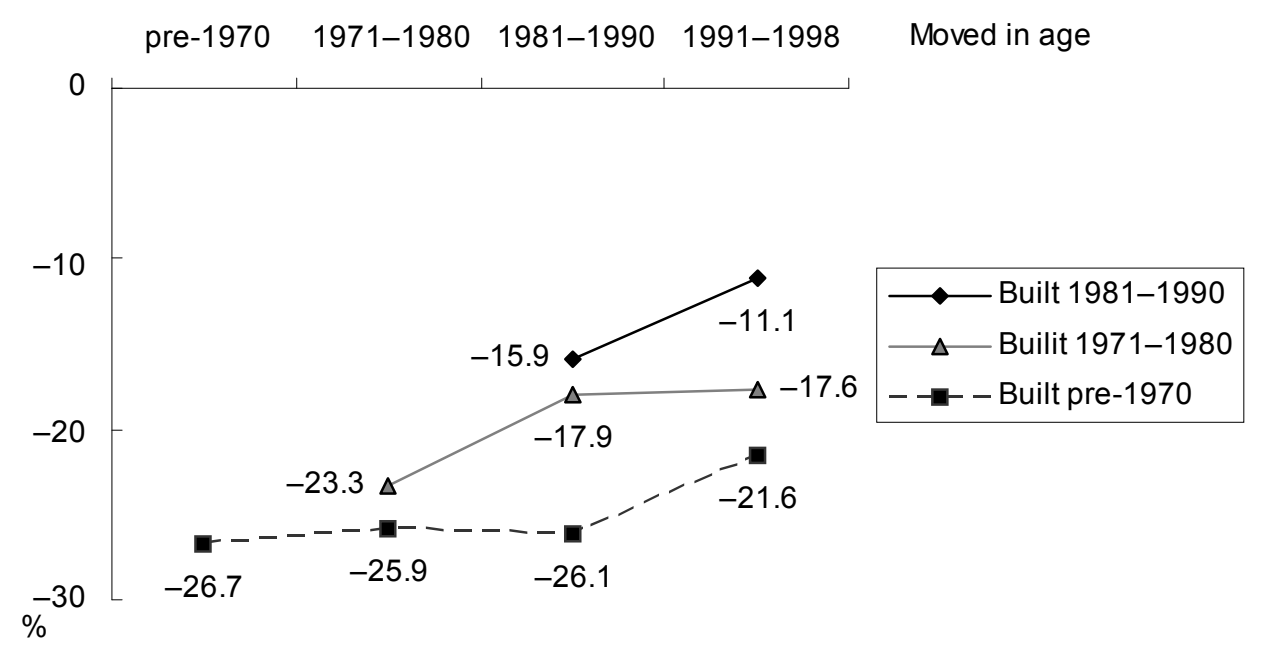

Fig. 4 The effect of tenure security on renter-occupied single-family housing 